\title{
ESTUDO DA PERMEABILIDADE DE SOLUÇÕES DE POLIACRILAMIDAS EM MEIO POROSO
}

\author{
CARVALHO SANTOS, J. S. ${ }^{1}$; OLIVEIRA, M. C. A. ${ }^{2}$; DUARTE, T. M. S. ${ }^{2}$; DUARTE, M. \\ M. L. ; BARROS NETO, E. L ${ }^{1}$.
}
${ }^{1}$ Universidade Federal do Rio Grande do Norte, Programa de Pós Graduação em Engenharia Química ${ }^{2}$ Universidade Federal do Rio Grande do Norte, Departamento de Engenharia Química E-mail para contato: dlucarvalho@yahoo.com.br

\begin{abstract}
RESUMO - A permeabilidade é uma propriedade física das rochas que pode ser influenciada pelas características químicas e geológicas dos fluidos injetados. Sabe-se que a microporosidade tem os seus efeitos sobre a porosidade e a permeabilidade de correlação. Os reservatórios carbonáticos são afetados pelas propriedades elásticas da rocha, que reduzem a pressão e a velocidade sônica dos reservatórios, conseqüentemente influenciando na recuperação final de hidrocarbonetos. O objetivo do trabalho foi avaliar a permeabilidade dos polímeros a base de poliacrilamidas em amostras de arenito Botucatu, com intuito de observar a viabilidade na recuperação avançada de petróleo. A partir dos resultados obtidos, observou-se que os polímeros aniônicos apresentaram pressões mais elevadas em comparação ao polímero não iônico pós-hidrolisado, e acreditase que esse comportamento esteja relacionado às viscosidades destes polímeros, que são mais acentuadas. Com isso, verifica-se que os polímeros aniônicos são mais viáveis para o processo de deslocamento de óleo em meio poroso.
\end{abstract}

\section{INTRODUÇÃO}

A porosidade e a permeabilidade são de fundamental importância na caracterização de um reservatório e na determinação de padrões de fluxo, com o intuito de otimizar a produção de petróleo. Na permeabilidade, há influências químicas, geológicas e dos fluidos injetados, e a partir disto, pode-se observar a variação das pressões no decorrer dos processos.

De acordo com Rahman e Pierson (2011), a microporosidade tem os seus efeitos sobre a porosidade e a permeabilidade de correlação. Os reservatórios carbonáticos são afetados pelas propriedades elásticas da rocha, reduzindo a pressão e a velocidade sônica dos reservatórios, e consequientemente influenciando na recuperação final de hidrocarbonetos. Por outro lado, a característica fractal da rocha pode provocar variações na permeabilidade, e durante o processo de carregamento, a porosidade da rocha sofre diminuições, acarretando na queda da permeabilidade e do coeficiente fractal (Zhaowanchum, et al. 2010). Outros autores observaram que o comportamento tensão - deformação em fraturas é um fator chave que rege 
a permeabilidade, com isso, examinaram as variações de permeabilidade induzidas através da abertura de um poço inclinado com formação naturalmente fraturada, comprovando que as mudanças de tensão e orientações das fraturas naturais influenciaram no processo (Zang, et al. 2007).

Por outro lado, há estudos por meio de redes neurais, mostrando que a porosidade é bastante linear ao som e às leituras de densidades, enquanto as transformações de permeabilidade comuns indicam relações não lineares entre a permeabilidade e as mesmas medidas físicas. Sabe-se que existe uma dependência adicional sobre a textura da rocha, a forma dos poros e a sua distribuição, juntamente com o teor de argila, tornando-a mais complicada do que para a porosidade (Helle et al, 2001). Da mesma forma, pesquisadores como Nie et al (2012), mostraram em seus resultados numéricos das simulações, que há diferenças óbvias entre permeabilidade dupla e modelos de permeabilidade individuais. Com isso, observaram que o comportamento de fluxo da permeabilidade em relação a pressão adimensional da modelagem de permeabilidade dupla é menor que a da modelagem de permeabilidade única. Isso indica que o fluxo de permeabilidade dupla acelera o aumento de energia durante a produção, porque esta considera o fornecimento de fluidos direto da matriz para poço.

A permeabilidade de uma rocha pode ser definida como a capacidade de a mesma permitir o fluxo do fluido através dos seus poros. Algumas rochas são formadas por sedimentos argilosos, possuindo valores muito baixos de permeabilidade. Os arenitos e calcários, por sua vez, possuem valores muito altos de permeabilidade, sendo responsáveis pela formação dos principais reservatórios de petróleo (Miranda, 2004). Na existência de mais de um fluido, a facilidade com que cada um se move é chamada permeabilidade efetiva. Por exemplo, se em um meio poroso estão fluindo água e óleo, tem-se permeabilidade efetiva da água e do óleo (Thomas, 2001).

Este trabalho tem como objetivo avaliar a permeabilidade dos polímeros a base de poliacrilamidas em rochas Botucatu, observando os respectivos comportamentos sob o efeito da pressão no meio poroso, de modo a analisar a sua possível aplicação em processos de recuperação avançada de petróleo.

\section{METODOLOGIA EXPERIMENTAL}

Na realização dos testes de permeabilidade em meio poroso, a princípio é feita a padronização das rochas reservatório, do tipo arenito Botucatu. Após isso, realiza-se a saturação com água salina, seguida do polímero e por fim, novamente injeção de água salina.

\subsection{Padronização da rocha reservatório}

As rochas-reservatório são padronizadas através de cortes na rocha bruta com uma serra copo diamantada, e os cilindros são posteriormente cortados por uma máquina serra no tamanho desejado. Como esses arenitos são bastante porosos, há a presença de impurezas, sendo necessário calciná-las a altas temperaturas. A calcinação da rocha foi realizada utilizando-se um forno mufla. Também, foi determinada a porosidade de cada amostra de 
rocha pela Equação 5.1, que representa o volume de um cilindro, e pela Equação 5.2, de porosidade.

$$
V_{\text {cilindro }}=r^{2} * \pi * L
$$

onde $V_{\text {cilindro }}$ é o volume do cilindro, $\mathrm{r}$ o raio do cilindro e L a sua altura.

$$
\phi=\frac{v_{v}}{v_{t}}
$$

sendo $\phi$ a porosidade, $V_{v}$ o volume de vazios e $V_{t}$ o volume total. O volume de vazios é normalmente denominado de volume poroso da rocha e é representado pelo símbolo $V_{P}$ (Rosa et al., 2006).

\subsection{Permeabilidade dos fluidos}

Para realização dos testes de permeabilidade foram utilizadas poliacrilamidas com cargas iônicas entre 0 e 70\%, que foram preparadas em água destilada: AH- 0\% (polímero não iônico pós-hidrolisado) e AN-30\% e AN-70\% (polímeros aniônicos) nas concentrações de 1000 e 1500 ppm. Suas respectivas viscosidades foram avaliadas em um reômetro Brookfield Viscometer - Brookfield Engineering Labs.

As rochas preparadas foram colocadas dentro de uma luva de borracha, conectadas por um disco radial com tubulações para a passagem do fluido. A luva foi introduzida no holder e pressurizada a 4,9 bar. Na conexão por onde o fluido é injetado, há um manômetro para medir a variação da pressão no decorrer do tempo de cada análise. Essas conexões foram acopladas nas celas que contêm os fluidos a serem injetados na rocha por meio de uma bomba de injeção.

\section{RESULTADOS E DISCUSSÃO}

O cálculo para a obtenção do volume poroso se dá através da Equação 5.3.

$$
V_{\text {poroso }}=t \frac{Q}{V_{P}}
$$

Sendo, $\mathrm{V}_{\text {poroso }} \mathrm{O}$ volume poroso, t o tempo, Q a vazão da bomba e Vp o volume de poros.

Na figura 3.1 é mostrado o comportamento do polímero pós-hidrolisado (AH-0\%) em meio poroso. Observa-se que a pressão durante a saturação com água salina era de 0,015 bar, e após a injeção do polímero a pressão variou entre 0,055 e 0,105.Ao retornar à injeção de água, ocorreu um decréscimo da pressão para 0,07 bar, mantendo-se praticamente constante em 0,045 bar no final do processo. Com isso, verifica-se que provavelmente os poros sofreram modificações, pois a pressão não voltou ao estado inicial. 


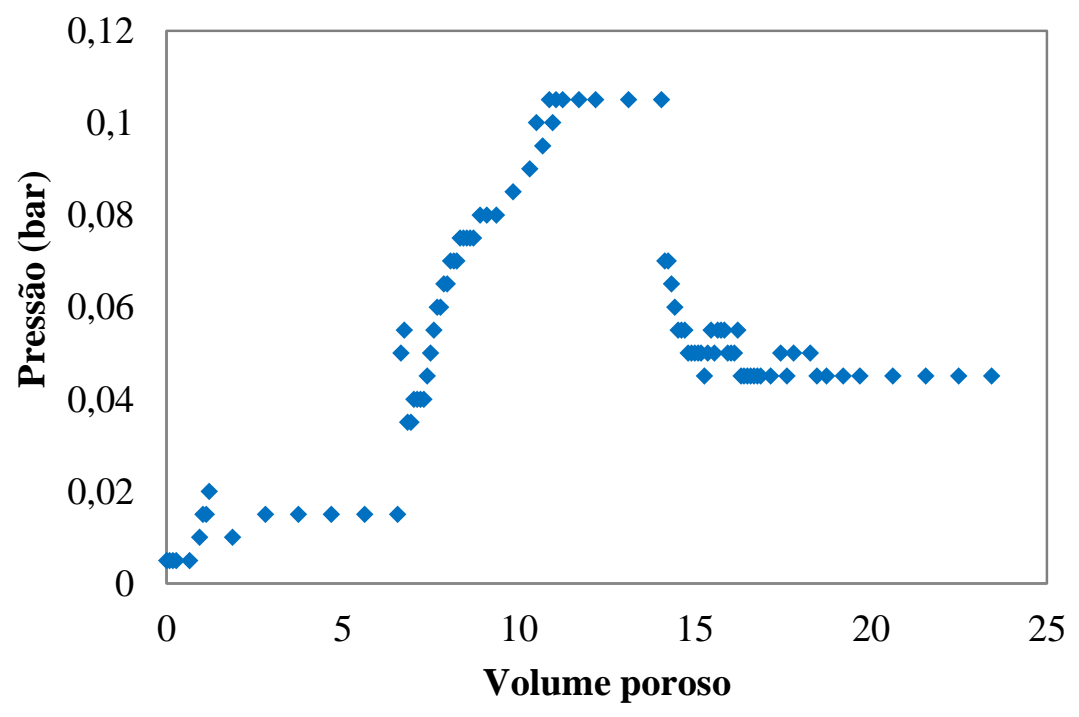

Figura 3.1 - Permeabilidade com o polímero AH-0\% a 1500 ppm.

A Figura 3.2 representa o comportamento do polímero aniônico (AN-30\%). Verificouse que a pressão durante a saturação com água salina permaneceu na faixa de 0,015 bar, mas ao se injetar o polímero foram obtidas pressões entre 0,030 e 0,315 bar e, ao reinjetar água, a pressão diminuiu para 0,185 bar e continuou a decrescer, mantendo-se, ao final do processo, constante em 0,000 bar. A partir disto, observa-se que os poros não sofreram obstrução, porque a pressão final foi menor que a inicial.

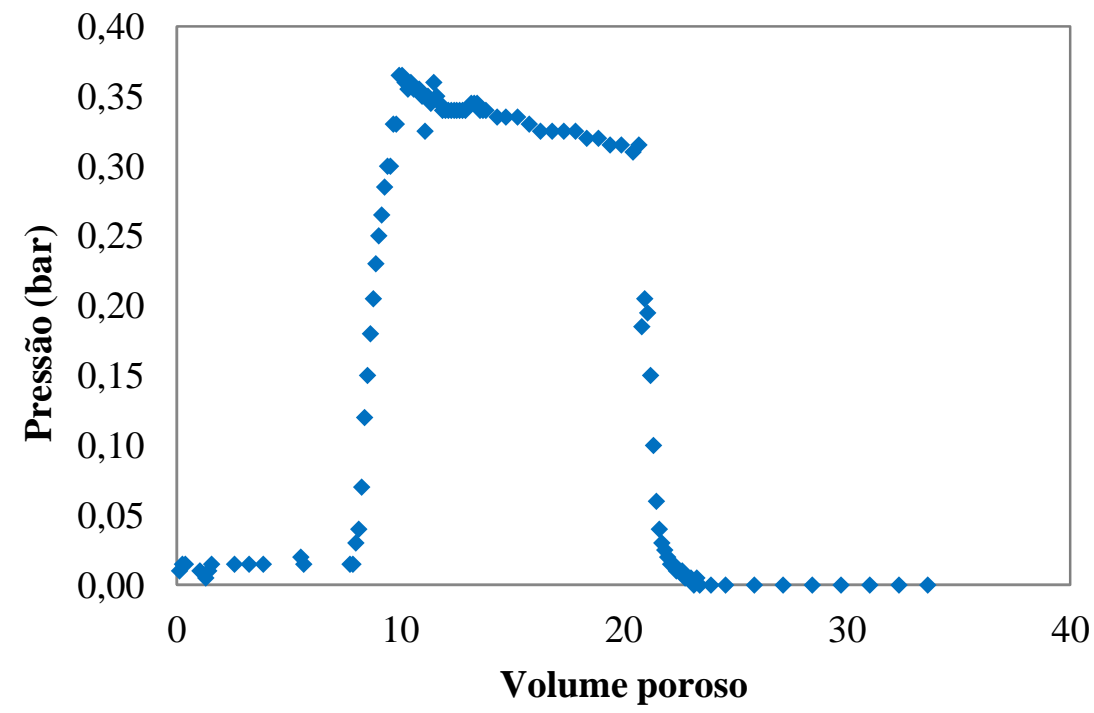

Figura 3.2 - Permeabilidade com o polímero AN-30\% a 1500 ppm. 
$\mathrm{Na}$ figura 3.3 está representado o comportamento reológico do polímero aniônico (AN-70\%). Constatou-se que a pressão durante a saturação com água salina foi de cerca de 0,025 bar, porém ao injetar o polímero a pressão permaneceu entre 0,090 e 0,365 bar e ao injetar água novamente a pressão foi praticamente constante, na faixa de 0,130 bar no decorrer do processo. De acordo com o comportamento da pressão, é provável que o polímero tenha ficado adsorvido na rocha.

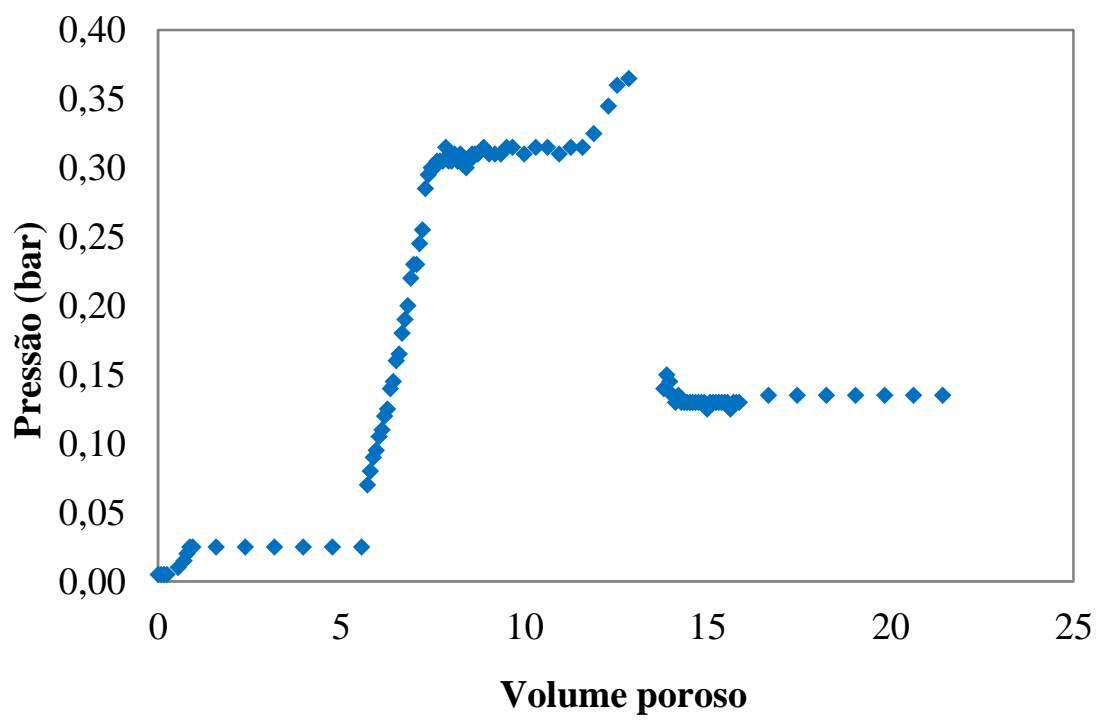

Figura 3.3 - Permeabilidade com o polímero AN-70\% a 1000 ppm.

Em outros estudos, a concentração crítica destes polímeros foi verificada através da viscosidade em diferentes concentrações. Diante disto, observa-se na Tabela 3.1 que a concentração crítica do polímero não iônico foi em 1000 ppm, e a dos aniônicos em 1500 ppm. Porém, os experimentos de permeabilidade foram realizados em $1000 \mathrm{ppm}$ para o polímero AN-70\%, no intuito de observar se nesta concentração haveria viabilidade. Quanto aos outros dois, os polímeros foram injetados na concentração de 1500 ppm.

Tabela 3.1 Viscosidade das soluções polimericas em diferentes concentrações.

\begin{tabular}{cccc}
\hline & \multicolumn{3}{c}{ Viscosidade (cP) } \\
\cline { 2 - 4 } C (ppm) & AH-0\% & AN-30\% & AN-70\% \\
\hline 1000 & 9,2 & 9,35 & 9,8 \\
1500 & 5,4 & 11,3 & 12,6 \\
\hline
\end{tabular}


O polímero AN-30\% mostrou-se viável em seu comportamento, enquanto que o $\mathrm{AH}$ $0 \%$ apresentou-se de forma inconstante. Acredita-se que este efeito esteja relacionado a uma super saturação de monômeros por estar acima da concentração crítica.

\section{CONCLUSÕES}

A partir dos resultados obtidos, verificou-se que os polímeros aniônicos apresentaram pressões máximas na faixa de 0,365 e 0,315 bar, e o polímero não iônico pós-hidrolisado em torno 0,105 bar. Acredita-se que o aumento das pressões esteja relacionado às viscosidades, enquanto o decréscimo delas pode estar correlacionado à concentração crítica e às cargas, porque o polímero AN-30\% apresentou um melhor comportamento e uma pressão final bem mais baixa que os demais. Isto significa que não houve adsorção do polímero pela rocha, ou seja, o meio poroso não sofreu deformações, tornando-o mais viável para o processo de recuperação avançada.

\section{AGRADECIMENTOS}

Os autores agradecem o apoio financeiro, em forma de bolsa de estudos, dada pela ANP e Petrobras.

\section{REFERÊNCIAS}

HELLE, H. B.; BHATT, A.; URSIN, B. Porosity and permeability prediction from wireline logs using artificial neural networks: a North Sea case study. Geophysical Prospecting, v. 49, p. 431-444, 2001.

MIRANDA, H. C. B.. Interpretação conjunta de dados de GPR e medidas de permeabilidade sobre um reservatório ciliciclástico falhado na bacia de tucano, NE Brasil. 2004. 127 f. Dissertação (Mestrado) - Departamento de Geologia, UFRN, Natal.

NIE, R.; MENG, Y.; JIA, Y.; ZHANG, F.; YANG, X.; NIU, X. Dual Porosity and Dual Permeability Modeling of Horizontal Well in Naturally Fractured Reservoir. Transp Porous Med, v. 92, p. 213-235, 2012.

RAHMAN, M. H.; PIERSON, B. J. Quantification of microporosity and Its effects on permeability and sonic velocity in miocene carbonate reservoirs, offshore Sarawak, Malaysia. IEEE. 2011, v. 978, p. 4577-1884.

ROSA, A. J.; CARVALHO, R. S.; XAVIER, J. A. D. Engenharia de reservatório de petróleo. Rio de Janeiro: Interciência, Petrobrás, 2006.

THOMAS, J. E. Fundamentos de Engenharia de Petróleo. Rio de Janeiro: Interciência: Petrobrás, 2001. 
ZHANG, J.; STANDIFIRD, W. B.; ROEGIERS, J. C.; ZHANG, Y. Stress-Dependent Fluid Flow and Permeability in Fractured Media: from Lab Experiments to Engineering Applications. Rock Mechanics and rock Engineering. 2007, v. 40, p. 3-21.

ZHAOWANCHUN; AICHI; WANGTINGTING; SUNCHENGYAN. A new definition on fractal porous rock damage variable and study on evolution characteristics of porosity-permeability. International Conference on E-Business and E-Government, p. 5031-5034, 2010. 